\title{
Correlação entre a atividade sérica da ceruloplasmina e os teores sérico e hepático de cobre em novilhas Nelore
}

[Ceruloplasmin serum activity correlation with copper serum and liver concentrations in Nelore heifers]

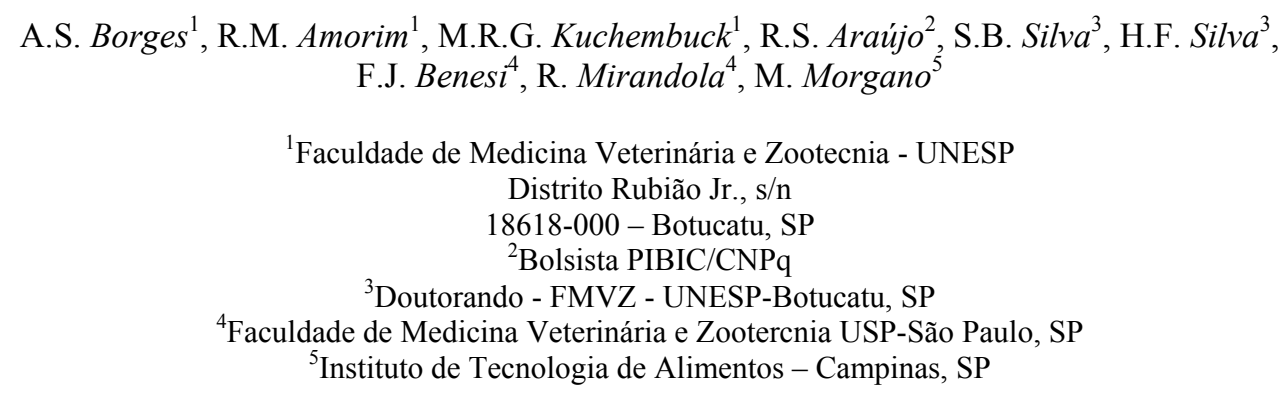

\section{RESUMO}

Avaliou-se a atividade oxidativa sérica da ceruloplasmina como indicadora dos teores sérico e hepático de cobre e compararam-se dois métodos de determinação da ceruloplasmina, pelo parafenileno e pela ortodianisidina. Foram colhidas 56 amostras de soro e de fígado (biópsias hepáticas) de novilhas Nelore para determinação da atividade sérica da ceruloplasmina e da concentração de cobre. As correlações entre a concentração sérica de cobre e a atividade sérica da ceruloplasmina determinadas pelos métodos do parafemileno e da ortodianisidina foram 0,75 e 0,62 , respectivamente. As correlações entre a concentração hepática de cobre e a atividade sérica da ceruloplasmina pelos métodos citados foram $0,15 \mathrm{e}$ 0,12 . Não foi observada correlação entre os valores séricos e hepáticos de cobre. A correlação entre determinação da atividade sérica de ceruloplasmina, que utilizou o parafenileno como substrato, e o cobre sérico foi maior do que a correlação entre esse mineral e o método que usou a ortodianisidina.

Palavras-chave: bovino, cobre, ceruloplasmina, biopsia hepática

\begin{abstract}
The ceruloplasmin oxidase activity as an indicator of serum and liver copper levels was evaluated and two different methods of ceruloplasmin determination (paraphenylen and ortodianisidine) were compared. Fifty six serum and liver samples from Nelore heifers were used to evaluate copper concentration and ceruloplasmin serum activity. The correlation coefficients between cooper serum values and ceruloplasmin serum activity using paraphenylen and ortodianisidine were 0.75 and 0.62 , respectively. The correlation between ceruloplasmin serum activity and copper liver concentrations were 0.15 and 0.12, respectively, for paraphenylen and ortodianisidine. No relationship between serum and liver copper levels was observed. Cooper serum determination by paraphenylen method showed higher correlation with liver copper level in comparison to copper serum determination by ortodianisidine method.
\end{abstract}

Keywords: bovine, copper ceruloplasmin, liver biopsy

Apoio: Fundação para o Desenvolvimento da Pesquisa na UNESP e Fundação de Amparo à Pesquisa do Estado de São Paulo Recebido para publicação em 13 de maio de 2003

Recebido para publicação, após modificações, em 23 de junho de 2004

E-mail: asborges@fmvz.unesp.br 


\section{INTRODUÇÃO}

As deficiências de elementos minerais são fatores que limitam a produtividade da indústria animal. A deficiência de cobre foi apontada como a mais encontrada em bovinos por todo o mundo (McDowell, 1999). Tokarnia et al. (1999), em artigo de revisão sobre deficiências minerais em bovinos e ovinos no Brasil, apontaram as deficiências de cobre, cobalto e zinco como as mais freqüentes.

Moraes et al. (1994) encontraram pastagens deficientes em cobre nas regiões de Mato Grosso, Mato Grosso do Sul, Goiás e Acre. Nesse estudo, a concentração desse elemento foi inferior ao requerido pelos animais em, aproximadamente, $\quad 50 \%$ das propriedades estudadas.

A deficiência marginal de cobre, por ser mais comum, acarreta mais prejuízo do que a deficiência severa. Taxas inadequadas de cobre na dieta podem causar diminuição do crescimento e queda dos índices reprodutivos, sem apresentar sinais clínicos patognomônicos (McDowell et al., 1993).

O estado nutricional rebanho quando ao cobre pode ser avaliado nos alimentos, na água, no soro e no fígado, ou ainda por determinação da atividade sérica da ceruloplasmina (Hidiroglou, 1980; Vermunt e West, 1994). A avaliação baseada em apenas um item pode levar a conclusões errôneas (Wikse et al., 1992).

Cerca de 40 a $70 \%$ do cobre absorvido é estocado no fígado, de onde é liberado quando há redução de consumo (Corah e Ives, 1991). A análise de amostras de fígado é confiável para avaliar a condição orgânica de cobre, cobalto, manganês, selênio e, eventualmente, zinco (Tokarnia et al., 1999).

A atividade oxidativa sérica da ceruloplasmina está relacionada com a concentração sérica de cobre, isto é, baixa concentração desse elemento está associada à menor atividade de ceruloplasmina. Um dos métodos mais empregados para verificação da atividade da ceruloplasmina é o da oxidação de parafenilenodiamina. $\mathrm{O}$ produto dessa reação é de cor púrpura, pode ser determinado por espectrofotometria e é o método de referência para a maioria das determinações (Ravin, 1961). Outro método descrito consiste na reação da ceruloplasmina com a ortodianisidina como substrato (Schosinsky et al., 1974; Paynter, 1982). Os métodos oxidativos detectam apenas a ceruloplasmina ligada ao cobre.

Blakley e Hamilton (1985) verificaram que a correlação entre a atividade sérica da ceruloplasmina e a concentração sérica de cobre foi de 0,83 e concluíram que ela pode ser utilizada como indicador do estado orgânico de cobre em bovinos. Amer et al. (1973) verificaram, em bezerros, correlação do 0,98 entre as mesmas variáveis, e constataram que $96,5 \%$ das diferenças na atividade de ceruloplasmina oxidase podem ser explicadas por alterações na concentração de cobre plasmático. Após a suplementação com cobre em bovinos deficientes, Kapoor e Mahadevan (1970) verificaram alta correlação entre os valores plasmáticos de cobre e a atividade sérica da ceruloplasmina. Cerone et al. (1998) verificaram redução da atividade sérica da ceruloplasmina em fêmeas bovinas com deficiência secundária induzida de cobre, pela administração de molibdênio. A correlação entre a ceruloplasmina sérica e o cobre hepático é baixa, ao redor de 0,35 (Kincaid, 1986).

Este trabalho teve o objetivo de comparar duas metodologias para avaliação da atividade sérica da ceruloplasmina e estimar a correlação entre ela e os teores séricos e hepáticos de cobre.

\section{MATERIAL E MÉTODOS}

Utilizaram-se 56 novilhas Nelore, não gestantes, com bom desempenho corporal e peso vivo de aproximadamente $330 \mathrm{~kg}$, colocadas em pasto de $B$. decumbens, em uma propriedade particular localizada no município de Paulistânia-SP. As pastagens foram submetidas à análises bromatológicas, obtendo-se os seguintes resultados: $\mathrm{N}=5 \mathrm{~g} / \mathrm{kg}, \mathrm{P}=0,8 \mathrm{~g} / \mathrm{kg}, \mathrm{K}=8 \mathrm{~g} / \mathrm{kg}, \mathrm{Ca}=$ $3 \mathrm{~g} / \mathrm{kg}, \mathrm{Mg}=2,6 \mathrm{~g} / \mathrm{kg}, \mathrm{S}=0,6 \mathrm{~g} / \mathrm{kg}, \mathrm{B}=6 \mathrm{mg} / \mathrm{kg}$, $\mathrm{Cu}=6 \mathrm{mg} / \mathrm{kg}, \mathrm{Fe}=153 \mathrm{mg} / \mathrm{kg}, \mathrm{Mn}=278 \mathrm{mg} / \mathrm{kg}$, $\mathrm{Zn}=23 \mathrm{mg} / \mathrm{kg}$ e $\mathrm{Mo}=2 \mathrm{mg} / \mathrm{kg}$. 
Foram colhidos $20 \mathrm{ml}$ de sangue em tubo especial a vácuo ${ }^{1}$, isento de contaminação com minerais, sem anticoagulante. Após retração parcial do coágulo e centrifugação, o soro, separado por aspiração, foi dividido em alíquotas e congelado a $-20^{\circ} \mathrm{C}$ para a posterior análise.

Realizaram-se biópsias hepáticas segundo Chapman Junior et al. (1963).

A atividade sérica da ceruloplasmina foi determinada no soro sangüíneo utilizando-se duas metodologias. Na primeira usou-se o parafenilenodiamino ${ }^{2}$ como substrato, segundo descrição de Ravin, (1961). Nesse método, a atividade da ceruloplasmina foi determinada pela taxa de oxidação do parafenilenodiamino à temperatura de $37^{\circ} \mathrm{C}$ e pH 6,0. Mediu-se em espectofotômetro o aparecimento de cor púrpura em conseqüência da oxidação. Realizou-se correção, devido à catálise oxidativa pelo $\mathrm{Cu}$ e Fe presentes nas amostras, utilizando-se branco em que a ceruloplasmina foi inibida pela azida sódica $^{3}$. Uma unidade de atividade é definida como o aumento de 0,001 na absorbância em 530nm após 30 minutos de reação. A reação de oxidação é aumentada pela exposição à luz, portanto, o procedimento foi realizado no escuro.

A segunda metodologia consistiu na determinação da concentração utilizando-se a ortodianisidina ${ }^{4}$ como substrato (Schosinsky et al., 1974). Ambas metodologias foram realizadas em duplicata e o resultado final expresso como média aritmética delas.

Para quantificação do cobre nas amostras de fígado e de soro empregou-se a técnica de espectrometria de emissão ótica com fonte de plasma de argônio indutivamente acoplada em espectrômetro simultâneo ${ }^{5}$.

Antes das análises foram realizados testes para a verificação do método de preparação do fígado bovino. Realizou-se a análise das amostras por via úmida (bloco digestor). Uma amostra de fígado certificada ${ }^{6}$, seca em estufa a $110^{\circ} \mathrm{C}$ por 12 horas, foi utilizada para a validação da metodologia.

Para determinação de cobre utilizou-se a metodologia da digestão ácida em bloco digestor $^{7}$ (Asp e Lund, 1992) como se segue: pesagem de $0,2000 \pm 0,0011 \mathrm{~g}$ da amostra de fígado bovino em tubos de vidro e adição de $15 \mathrm{ml}$ de ácido nítrico concentrado; aquecimento do bloco digestor a partir de $50^{\circ} \mathrm{C}$, com aumento de $10^{\circ} \mathrm{C}$ a intervalos de 30 minutos até atingir $160^{\circ} \mathrm{C}$; aquecimento até o volume atingir aproximadamente $5 \mathrm{ml}$; transferência das amostras para balões volumétricos de $25 \mathrm{ml}$, completando-se o volume com ácido clorídrico $5 \% \mathrm{v} / \mathrm{v}$.

Para a determinação do cobre sérico, o método de preparação baseou-se no procedimento descrito por Evenson e Warren (1975), isto é, colocação de $400 \mu \mathrm{l}$ da amostra de soro em balões volumétricos de $10 \mathrm{ml}$ e complemento do volume com ácido clorídrico $5 \%$ v/v. As quantificações também foram realizadas por espectrometria de emissão óptica com fonte de plasma de argônio indutivamente acoplada.

Realizou-se análise descritiva e estimou-se correlação de Pearson entre a atividade sérica da ceruloplasmina e os teores sérico e hepático de cobre (Zar, 1984).

\section{RESULTADOS E DISCUSSÃO}

A Tab. 1 apresenta as médias, os desvios-padrão e as medianas da atividade sérica da ceruloplasmina (métodos do parafenileno e da ortodianisidina), do cobre sérico $(\mathrm{mg} / \mathrm{l})$ e do hepático ( $\mathrm{mg} / \mathrm{kg}$ / matéria seca).

\footnotetext{
${ }^{1}$ Becton \& Dickinson Ind. Cirúrgicas Ltda, Brasil.

${ }^{2}$ Ref 16165 - Riedel-deHaën

${ }^{3}$ Labsynth Produtos para Laboratório Ltda.

${ }^{4}$ Ref. D3252 - Sigma.

${ }^{5}$ BAIRD, modelo ICP 2000 (Massachusetts, USA).
}

\footnotetext{
${ }^{6} 1577 \mathrm{~b}$ - Bovine Liver - National Institute of Standards and Technology (NIST).

${ }^{7}$ Sistema aberto, modelo TE-040-25-TECNAL.
} 
Tabela 1. Média, desvio-padrão (DP) e mediana da atividade sérica da ceruloplasmina, (UI/l) método do parafenileno e da ortodianisidina, do cobre sérico (mg/l) e cobre hepático ( $\mathrm{mg} / \mathrm{kg} / \mathrm{MS})$ em novilhas Nelore

\begin{tabular}{lcccc} 
& $\begin{array}{c}\text { Ceruloplasmina } \\
\text { parafenileno }\end{array}$ & $\begin{array}{c}\text { Ceruloplasmina } \\
\text { ortodianisidina }\end{array}$ & $\begin{array}{c}\text { Cobre } \\
\text { sérico }\end{array}$ & $\begin{array}{c}\text { Cobre } \\
\text { hepático }\end{array}$ \\
\hline Média \pm DP & $250,09 \pm 51,27$ & $15,93 \pm 9,44$ & $0,75 \pm 0,14$ & $299,58 \pm 86,56$ \\
Mediana & 242,50 & 16,00 & 0,73 & 289,20 \\
\hline
\end{tabular}

$\mathrm{MS}=$ matéria seca.

A média do cobre hepático está dentro dos valores considerados normais para bovinos, de 100 a $300 \mathrm{mg} / \mathrm{kg} / \mathrm{MS}$ segundo Fick et al. (1979) ou de 100 a $400 \mathrm{mg} / \mathrm{kg} / \mathrm{MS}$ segundo McDowell (1992). Os valores encontrados, 132 a $545 \mathrm{mg} / \mathrm{kg} / \mathrm{MS}$, mostram a variação individual dos animais, pois eles foram mantidos juntos e sob o mesmo manejo nos últimos dois anos, fato também observado por Suttle (1986). Os resultados são semelhantes aos de Lisbôa et al. (1996).

A média do cobre sérico está dentro dos limites considerados normais, de 0,7 a $1,4 \mathrm{mg} / 1$ segundo Fick et al. (1979) ou de 0,6 a $1,5 \mathrm{mg} / \mathrm{l}$ segundo McDowell (1992). Os valores hepáticos de cobre estão mais próximos do limite superior e os séricos de cobre estão no limite inferior aos citados por esses autores.

A avaliação individual do cobre sérico revelou 22 animais com valores abaixo dos $0,7 \mathrm{mg} / 1$ citados por Fick et al. (1979) e quatro se se considerar 0,6mg/l citado por McDowell (1992). Segundo esse autor, valores abaixo de $0,6 \mathrm{mg} / 1$ seriam indicativos de deficiência em ovinos e bovinos. Entretanto, os animais com concentração sérica abaixo de $0,6 \mathrm{mg} / 1$ apresentaram níveis normais de cobre hepático.

Segundo Claypool et al. (1975), os valores séricos só são acompanhados de baixos valores hepáticos quando encontram-se abaixo de 0,5mg/l. Das 101 observações realizadas por esses autores, nas quais os níveis plasmáticos estavam abaixo de $0,5 \mathrm{mg} / 1$, apenas quatro apresentaram valores hepáticos acima de $40 \mathrm{mg} / \mathrm{kg} / \mathrm{MS}$. No presente trabalho apenas um animal estava com valor sérico abaixo de $0,5 \mathrm{mg} / 1$, contudo, o valor hepático de cobre foi normal. Observou-se correlação negativa entre os valores séricos e hepáticos de cobre $(r=-0,1)$, já registrada por Fichtner et al. (1988).
Os menores valores hepáticos não foram acompanhados pelos menores valores séricos, já que a homeostasia impede que isso ocorra até que as reservas hepáticas estejam muito reduzidas. Dessa forma, pode-se sugerir que os valores hepáticos são mais confiáveis que os valores séricos para avaliar o estado nutricional de cobre no organismo.

As médias e os desvios-padrão obtidos para a atividade sérica da ceruloplasmina pelos métodos do parafenileno e da ortodianisidina foram $250,09 \pm 51,27 \mathrm{UI} / 1 \quad$ e $\quad 15,93 \pm 9,44 \mathrm{UI} / 1$, respectivamente. $\mathrm{Na}$ ordem de citação dos métodos, a correlação entre a atividade sérica da ceruloplasmina e a concentração sérica de cobre foi de 0,75 e 0,62. Nessa mesma ordem, a correlação entre a atividade sérica da ceruloplasmina e a concentração de cobre hepático foi de 0,15 e 0,12 . Os resultados assemelham-se aos de Kincaid (1986). A correlação foi menor que a citada por Amer et al. (1973) e por Blakey e Hamilton (1985), ao utilizarem o parafenileno como substrato de reação. Isso decorre em razão da correlação nula entre os valores de concentração de cobre sérico e hepático.

Os resultados deste experimento mostram que é possível indicar os animais com maior ou menor valor de cobre sérico com base na determinação da atividade sérica da ceruloplasmina, confirmando as observações de Blakey e Hamilton (1985) e Kincaid (1986). A correlação observada entre a atividade da ceruloplasmina pelo método da ortodianisidina e o cobre sérico foi menor do que a correlação entre esse mineral e a atividade da ceruploplasmina obtida pelo método do parafenileno. Isto ocorreu em razão da presença de um único valor discrepante. A técnica de determinação da atividade da ceruloplasmina que utiliza a ortodianisidina como substrato é mais fácil de ser realizada, pois a reação é inibida pela adição de azida sódica 
(Scosinsky et al., 1974), o que facilita o procedimento de leitura. Além disso, essa reação pode ser realizada com reagentes preparados com antecedência, o que não ocorre com o outro método. Entretanto, a reação com a ortodianisidina apresenta resultado muito baixo na sua leitura final, o que dificulta a percepção de pequenas variações. Outra desvantagem da técnica consiste na utilização de dois reagentes tóxicos: a ortodianisidina e o ácido sulfúrico a $50 \%$.

\section{CONCLUSÕES}

A correlação entre o método de determinação da atividade sérica de ceruloplasmina utilizando-se o parafenileno como substrato e a concentração de cobre sérico é maior do que a correlação entre esse mineral e a metodologia da ortodianisidina. A atividade sérica de ceruloplasmina é um indicador indireto da concentração sérica de cobre, permitindo que seja utilizada como método de triagem para auxiliar no diagnóstico de deficiência marginal de cobre em bovinos.

\section{REFERÊNCIAS BIBLIOGRÁFICAS}

AMER, M.A., ST-LAURENT, G.J., BRISSON, G.J. Supplemental copper and selenium for calves: efects upon ceruloplasmin activity and liver copper concentration. Can. J. Physiol. Pharmacol., v.51, p.649-654, 1973.

ASP, T.N.; LUND, W. Elemental analysis of bovine liver by inductively coupled plasma atomic emission-espectrometry by using a simple dissolution procedure. Talanta, v.39, p.563-566, 1992.

BLAKLEY, B.R.; HAMILTON, D.L. Ceruloplasmin as an indicator of copper status in cattle and sheep. Can. J. Comp. Med., v.49, p.405-408, 1985.

CERONE, S.I.; SANSINANEA, A.S.; STREITENBERGER, S.A. et al. The effect of copper deficiency on the peripheral blood cells of cattle. Vet. Res. Com., v.22, p.47-57, 1998.

CHAPMAN JUNIOR, H.L.; COX, D.H.; HAINES, C.H. et al. Evaluation of the liver biopsy technique for mineral nutrition studies with beef cattle. J. Anim. Sci., v.22, p.733-737, 1963.

CLAYPOOL, D.W.; ADAMS, F.W.; PENDELL, H.W. Relationship between the level of copper in the blood plasma and the liver of cattle. J. Anim. Sci., v.41, p.911-914, 1975.

CORAH, L.H.; IVES, S. The effects of essential trace minerals on reproduction in beef cattle. Vet. Clin. North Am.: Food Anim. Pract., v.7, p.4157, 1991.

EVENSON, M.A.; WARREN, B.L. Determination of serum copper by atomicabsorption, with use of graphite cuvette. Clin. Chem., v.21, p.619-625, 1975.

FICK, K.R.; McDOWELL, L.R.; MILES, P.H. et al. Methods of mineral analysis for plant and animal tissues. 2.ed. Gainesville: University of Florida, 1979. 90p.

HIDIROGLOU, M. Trace elements in fetal and neonate ruminant: A review. Can. Vet. J., v.21, p.328-335, 1980.

KAPOOR, U.R.; MAHADEVAN, V. Effect of copper and cobalt suplementation on ceruloplasmin $\mathrm{Cu}$ and total copper in bovine plasma and their interrelationship. Indian Vet. J., v.47, p.878-881, 1970.

KINCAID, R.; GAY, C.C.; KRIEGER, R.I. Relationship of serum and plasma copper and ceruloplasmin concentrations of cattle and the effects of whole blood sample storage. Am. J. Vet. Res., v.47, 1157-1159, 1986.

McDOWELL, L.R. Minerais para ruminantes sob pastejo em regiões tropicais enfatizando o Brasil. 3.ed. Gainesville: University of Florida, 1999. 92p.

McDOWELL, L.R. Minerals in animal and human nutrition. San Diego: Academic, 1992. $524 \mathrm{p}$.

McDOWELL, L.R.; CONRAD, J.H.; HEMBRY, F.G. Minerales para ruminantes en pastoreo en regiones tropicales. 2.ed. Gainesville: University of Florida, 1993. 77p.

MORAES, S.S.; SILVA, G.N.; DÕBEREINER, J. Microelementos minerais e a "cara inchada" dos bovinos. Pesq. Vet. Bras., v.14, p.25-33, 1994. 
PAYNTER, D.I. Differences between serum and plasma ceruloplasmin activities and copper concentrations: investigation of possible contributing sectors. Austr. J. Biol. Sci., v.35, p.353-361, 1982.

RAVIN, H.A. An improved colorimetric enzymatic assay of ceruloplasmin. J. Lab. Clin. Med., v.58, p.161-168, 1961.

SCHOSINSKY, K.H.; LEHMANN, H.P.; BEELER, M.F. Measurement of ceruloplasmin from its oxidase activity in serum by use of odionisidine dihidrochloride. Clin. Chem., v.20, p.1556-1563, 1974.

SUTTLE, N.F. Copper deficiency in ruminants; recent developments. Vet. Rec., v.119, p.519$522,1986$.
TOKARNIA, C.H.; DÖBEREINER, J.; MORAES, S.S. et al. Deficiências e desequilíbrios minerais em bovinos e ovinos revisão de estudos realizados no Brasil de 1987 a 1998. Pesq. Vet. Bras., v.19, p.47-62, 1999.

VERMUNT, J.J.; WEST, D.M. Predicting copper status in beef cattle using serum copper concentrations. New Zeal. Vet. J., v.42, p.194195, 1994.

WIKSE, S.E.; HERD, D.; FIELD, R. et al. Diagnosis of copper deficiency in cattle. $J$. Am. Vet. Med. Assoc., v.200, p.1625-1629, 1992.

ZAR, J.H. Biostatistical analysis. Englewood Clifs: Prentice-Hall,1984. 718p. 